\title{
Change of Young's Module on Steel Specimens with Corrosion by Experiment
}

\author{
Antonio Shopov and Borislav Bonev
}

\begin{abstract}
Nowadays, corrosion on steel structures is a common occurrence. The reasons that lead to the appearance of corrosion in structures are well-know as well as its negative impact of them. The possibility of re-use corroded steel elements into the construction should be ascertained and how this would affect the calculation and the design of the structure. We conducted an experiment to determine how the modulus of elasticity of corroded steel specimens was changed. We applied an electrochemical accelerated corrosion method to our S355JR steel specimens. After that we tensile- tested them, we took the values from the stress-strain diagrams and calculated the module change. We also applied the stochastic way of processing of the results. We have reached a conclusion that corrosion indicates a serious impact on the modulus of elasticity, even leading to a change of material, i.e. from ductile material, it subsequently becomes a brittle material, which circumstance should be taken into account in the re-use of corroded elements in their calculation and design.
\end{abstract}

Index Terms-Young's module, corrosion, accelerated corrosion, steel specimen.

\section{INTRODUCTION}

There are abandoned steel construction elements everywhere, whose corrosion is in advanced stages. Photographs of such steel construction elements are shown in Fig. 1. Ways should be sought to re-use these highly corroded steel elements, which would improve the environment.

The mechanism for determining mechanical properties resulting from corrosion and stress corrosion is also complicated by additional factors such as energy accumulation, environmental impact, action of sulphate-restoring bacteria, electrochemical and destructive processes in a structural layer [1].

There are many studies [2]-[11], [13]-[17] in the field of altering the mechanical properties of corroded steels, all of which examine stress-strain problems and their possible characterization, and some formulas or corresponding derived dependencies are also available in some of them. Also, a theoretical-computational model is available for calculating the stress of corrosion elements [3]. Corrosion has been found to cause an effect on the spring constant [4].

At present, the possibility of using corroded steel elements in construction as a type of reuse has not been fully investigated [2].

Corrosion has been found to cause significant changes in

Manuscript received January 16, 2019; revised April 12, 2019. This research received is funding by "Hyosel" Ltd., Sofia, Bulgaria.

A. Shopov and B. Bonev are with the Strength of Materials Department, Technical University of Sofia, 8 Kliment Ohridski Blvd., 1000 Sofia, Bulgaria (e-mail: shopoff@mail.bg, bonev@ecad.tu-sofia.bg). the structure of steel as a carrier, but from a practical point of view how to modify its dependence is not clear yet. By its very nature, the Young's module represents a material property that is determined for each type of steel, and it is that measures the stiffness of a solid material, which is related to the linear deformation (Hooke's law). The purpose of this study is the ascertainment of how the Young's modulus is modified in corroded steel specimens and the possibility to use the corroded steel elements carrier again in structures.

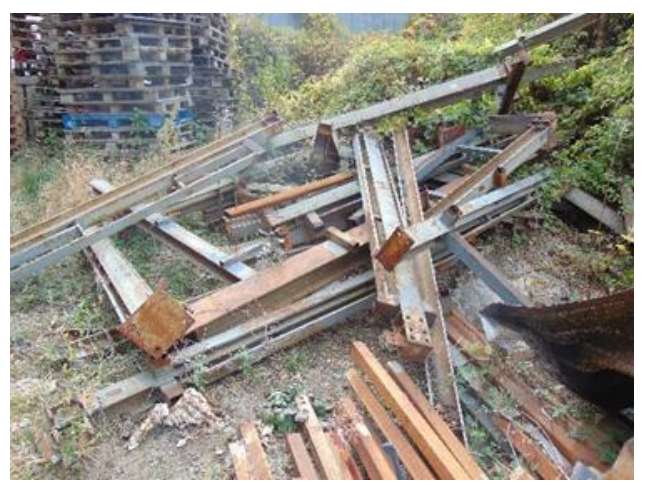

Fig. 1. Corroded steel elements, which may be reused in construction and structures.

\section{MATERIALS AND METHODS}

\section{A. Electrochemical Method}

The acceleration of the corrosion process is accomplished by using an external source of direct current and anodic dissolution of the steel. The test sample is connected to the positive pole of the source (anode) and the negative is connected to a stainless-steel plate or other metal inert (cathode). A fixed current is applied for a given amount of time in order to achieve a certain degree of corrosion. We use this method [4], [17], as well as other researches [5]-[11]. With respect to the stabilized parameter, the methods of electrochemical corrosion are two - potentiostatic (when stabilized parameter is the voltage between the anode and cathode) and galvanostatic (when the stabilized parameter is the current flowing through the test specimen).

The electrical resistance of the test specimen changes in the process of material loss. Furthermore, the chemical composition of the electrolyte changes, respectively its electrical resistance. Based on Faraday's formula, it follows that the weight loss rate is proportional to the current flowing through the test specimen. Therefore, if the potentiostatic method is used, periodic voltage correction would be necessary to maintain a constant loss of material rate. The current value depends on the resistance of the test sample and the resistance of the electrolyte. The current through the test specimen can be determined by Ohm's Law: 


$$
I_{\text {specimen }}=V_{\mathrm{A}-\mathrm{K}} /\left(R_{\text {specimen }}+R_{\text {electroliyte }}\right),
$$

where $I_{\text {specimen }}$ - current through the test specimen, $R_{\text {specimen }}-$ electrical resistance of the test specimen, $R_{\text {electrolyte }}-$ electrical resistance of the electrolyte, $V_{\mathrm{A}-\mathrm{K}}-$ voltage between the anode and the cathode.

In the present study, the use of a galvanostatic method was chosen to avoid periodic adjustment of voltage between anode and cathode. In addition, the time required for processing of the test specimen to obtain a certain weight loss can be calculated. The method requires a more complex schematic implementation than the potentiostatic method. The galvanostatic method is widely used in electrochemical processes [10], [11]. An individual current stabilizer for each sample is needed in order to ensure a stable current through each of the steel specimens.

A system for electrochemical corrosion using the galvanostatic method, which is also applicable to the study of other types of metallic elements used in construction, has been developed for the present study. The system contains a 75 adjustable current stabilizers and DC switching power supply. A block diagram of the developed system is shown in Fig. 2. For the implementation of the individual current stabilizers, the integrated circuit LM317 is used. The circuit diagram of one current stabilizer is shown in Fig. 3 [12].

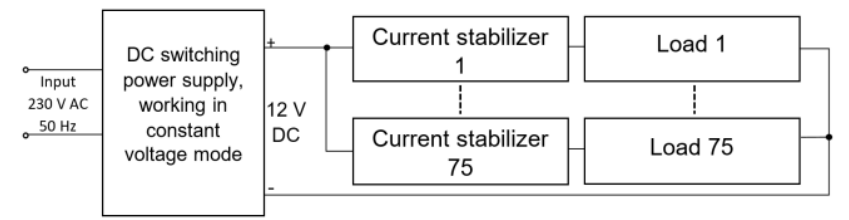

Fig. 2. Block diagram of the developed system for electrochemical corrosion.

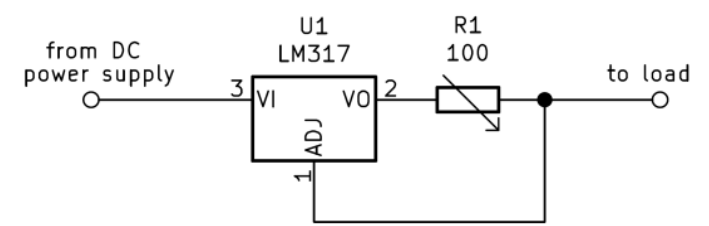

Fig. 3. Circuit diagram of one current stabilizer.

The output stabilized current of each channel can be adjusted smoothly in the range of $16 \mathrm{~mA}$ to $200 \mathrm{~mA}$ at the selected resistance for R1 of $100 \Omega$. The value of the output stabilized current is determined by the following equation [13]:

$$
\mathrm{I}[\mathrm{A}]=1.25 \mathrm{~V} / \mathrm{R} 1 \text {. }
$$

The used integrated circuit LM317 has a built-in thermal protection that limits the output power [12]. This greatly enhances the reliability of the developed system. With the selected supply voltage of $12 \mathrm{~V}$, with an output current of more than $100 \mathrm{~mA}$, it is necessary to use additional cooling of the integrated circuit, as the thermal resistance junction-case of the integrated circuit is $50{ }^{\circ} \mathrm{C} / \mathrm{W}$. For additional cooling, active fan cooling is used.

The chosen schematic solution allows parallel connection of the current stabilizers in order to obtain higher current. In this case, the output current is the sum of the output currents of the individual current stabilizers. For our experiment we chose a corrosive category C5 (very high) according ISO
14713 and our steel specimens need to be ready for tensile test after 14 days. That means, a current of $300 \mathrm{~mA}$ needs to be chosen, in which the percentage of the loss of material for 24 hours, using the Faraday formula is approximately:

$$
\eta[\%]=100 \times M \times I \times t /(W \times z \times F)=1,62 \%,
$$

where $W[\mathrm{~g}]$ is the weight of the original steel specimen, $z$ is the valence of the ion $\left(z=2,5\right.$ is the average value for $\mathrm{Fe}^{2+}$ and $\mathrm{Fe}^{3+}$ ions of the corrosion products), $F=96484 \mathrm{C} / \mathrm{mol}$ is the Faraday constant, $M=56 \mathrm{~g} / \mathrm{mol}$ is the atomic mass of the ferric-Ion, $I[\mathrm{~A}]$ - electrical current through the test specimen, $t[\mathrm{~s}]$ - time duration.

To realize the selected current of $300 \mathrm{~mA}$, each test specimen is connected to three parallel-connected channels with a set stabilization current for each channel of $100 \mathrm{~mA}$ in order to avoid the risk of current limiting due to integrated circuit built-in thermal protection activated in case of overheating. Such an eventual overheating and subsequent current reduction will lead to the reduction of the corrosion rate for certain test specimens. The used experimental set-up is shown in Fig. 4 and Fig. 5.

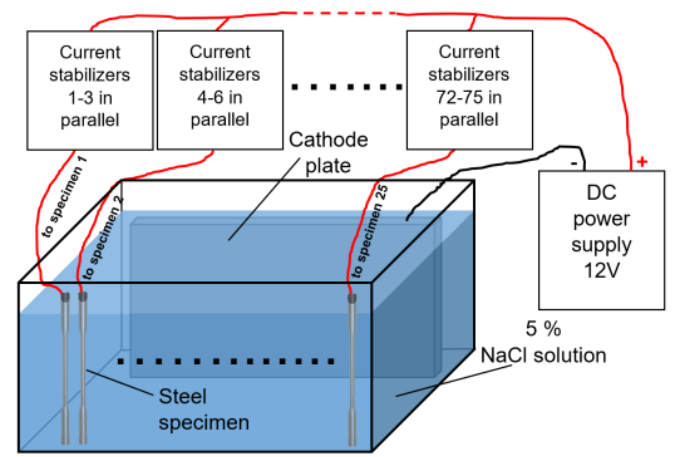

Fig. 4. Block scheme of the experimental setup.

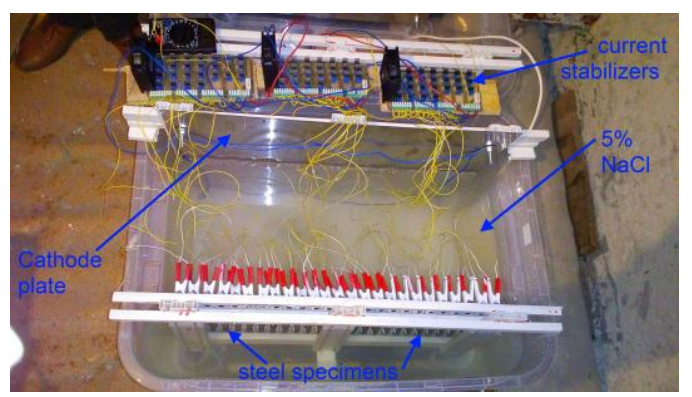

Fig. 5. Moment of acceleration corrosion process.

\section{B. Steel specimen}

The choice of steel specimen is a complicate task and depends of some factors. The authors have chosen what dimensions to be used on their sample [13]-[16].

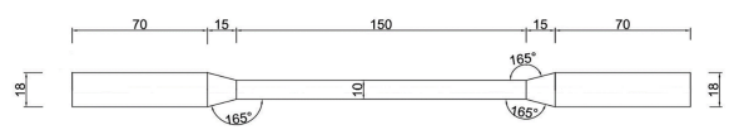

Fig. 6. Dimension of steel specimen [17].

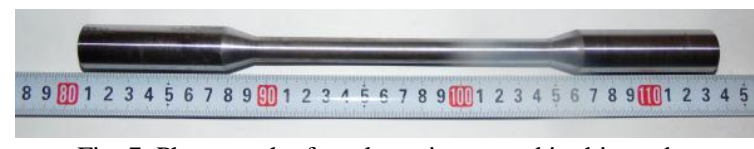

Fig. 7. Photograph of steel specimen used in this study. 


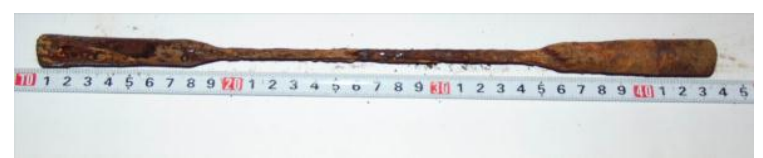

Fig. 8. Steel specimen after acceleration corrosion process.

Considering the classical theory of strength of materials, recommend steel specimen parallel length to be $15 \mathrm{~d}$, considering this factor and the requirements set in the standard ISO 6892-1:2016, where parallel length is given, our steel specimens need to be with dimensions [17], shown in Fig. 6 and Fig. 7. The photographs of the steel specimens after the acceleration corrosion process is shown in Fig. 8.

According standard ISO 8407:2009, we remove a corrosion product from our steel specimens in hydrochloric acid [16,17] - $10 \mathrm{~min}$, in solution of $500 \mathrm{ml} \mathrm{HCl}$

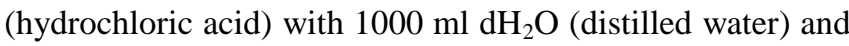
$3.5 \mathrm{~g}\left(\mathrm{CH}_{4}\right)_{6} \mathrm{~N}_{4}$ (hexamethylenetetramine) on temperature $20^{\circ} \mathrm{C}$ [17]. The used way to remove a corrosion product is shown on Fig. 9.
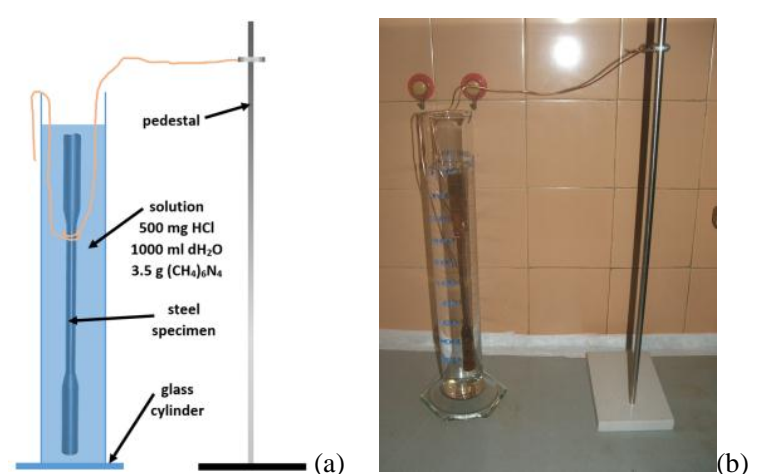

Fig. 9. Remove of the corrosion products from steel specimen: (a) principle scheme; (b) photograph.

It is good to mention, that the diameter of the steel specimen is changed and in every cross-section from parallel length the diameter is different. From our 25 steel specimens, we tested 20, another 5 are left as control samples (according to the rules of laboratory test procedure).

We tensile tested our specimens on universal testing machine MESSPHYSIK model BETA200-7/6x14 according to the standard ISO 6892-1:2016. Moment of tensile test of corroded steel specimens are shown in Fig. 10.

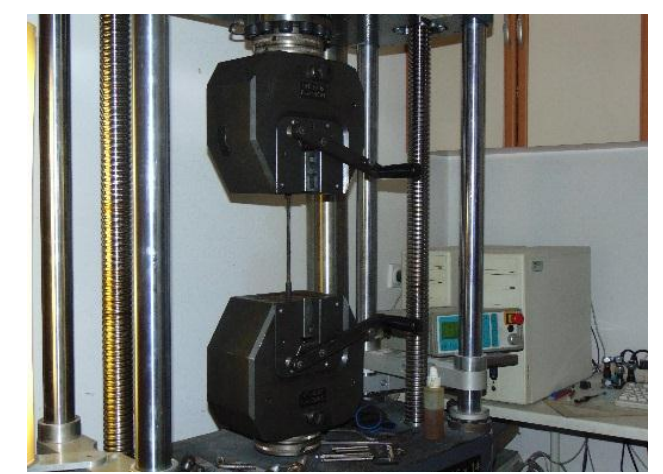

Fig. 10. Moment of tensile test of corroded steel specimen.

\section{Material}

In Bulgaria one of the most popular types of construction steel is S355JR. We perform a metal analysis for the determination of the chemical composition with Spector device "Spectrotest - TXC02; S/N 4S0007; analyzer: Fe-01MO; standard sample: RH 31/12, S3-2; type of probe: SL75060798", the results are given in Table I. After the results are obtained from device, we reached the decision that our steel is S355JR, according standard EN 10025-2-2004

TABLE I: CHEMICAL COMPOSITION ON STEEL SPECIMEN

\begin{tabular}{cccccccc}
\hline \hline \multicolumn{7}{c}{ Chemical composition, [\%] } \\
\hline $\mathrm{C}$ & $\mathrm{Si}$ & $\mathrm{Mn}$ & $\mathrm{P}$ & $\mathrm{S}$ & $\mathrm{Cr}$ & $\mathrm{Ni}$ & $\mathrm{Cu}$ \\
0.23 & 0.52 & 1.554 & 0.03 & 0.04 & 0.27 & 0.27 & 0.53 \\
\hline \hline
\end{tabular}

From the classic diagram (Fig. 11) we calculated (by Hooke's law) a change of Young's module for the value of stress which will be studied - Table II.

\begin{tabular}{llllllll}
\multicolumn{6}{c}{ TABLE II: VALUE ON STRESS AND YOUNG'S MODULE (S355JR) } \\
\hline$\sigma,[\mathrm{MPa}]$ & 50 & 100 & 150 & 200 & 250 & 300 & 350 \\
$\mathrm{E},[\mathrm{GPa}]$ & 96.1 & 124.8 & 148.3 & 167.6 & 183.8 & 198.2 & 210.7 \\
\hline \hline
\end{tabular}

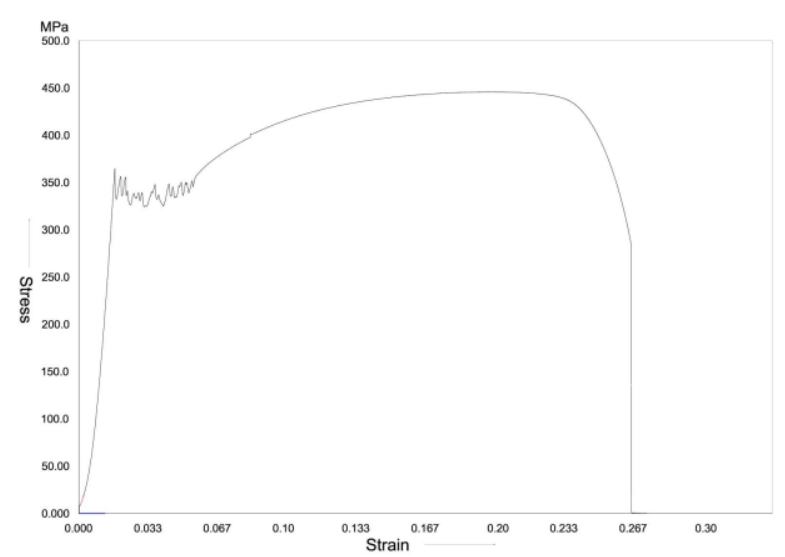

Fig. 11. Classic stress-strain diagram of steel S355JR.

\section{RESULTS}

\section{A. Results from Experiments}

In Fig. 12 are shown stress-strain diagrams of corroded steel specimens. The minimum diameter is shown for each stress-strain diagram. Fig. 13 shows change of weight and diameter after acceleration corrosion process for each test sample.

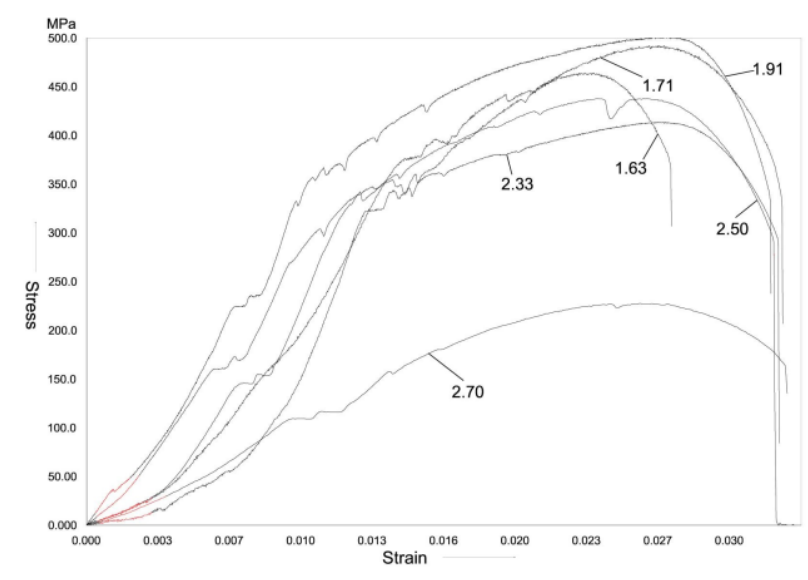

(a) 


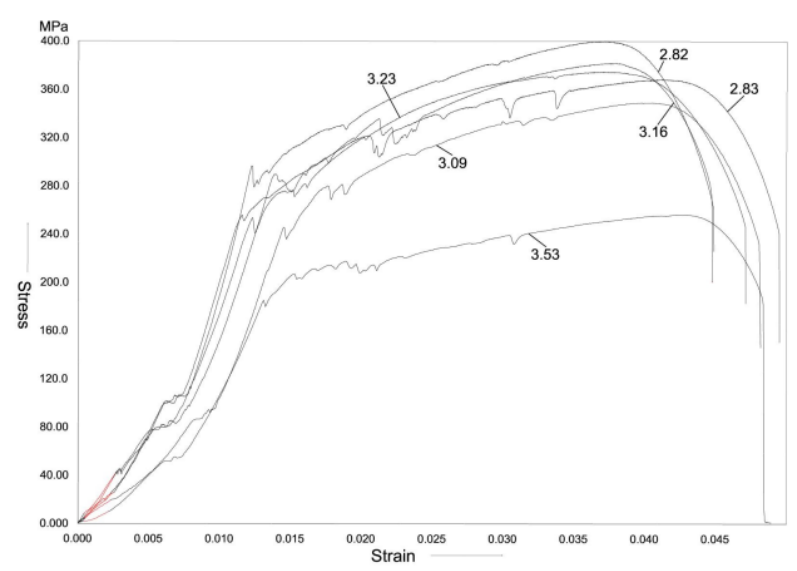

(b)

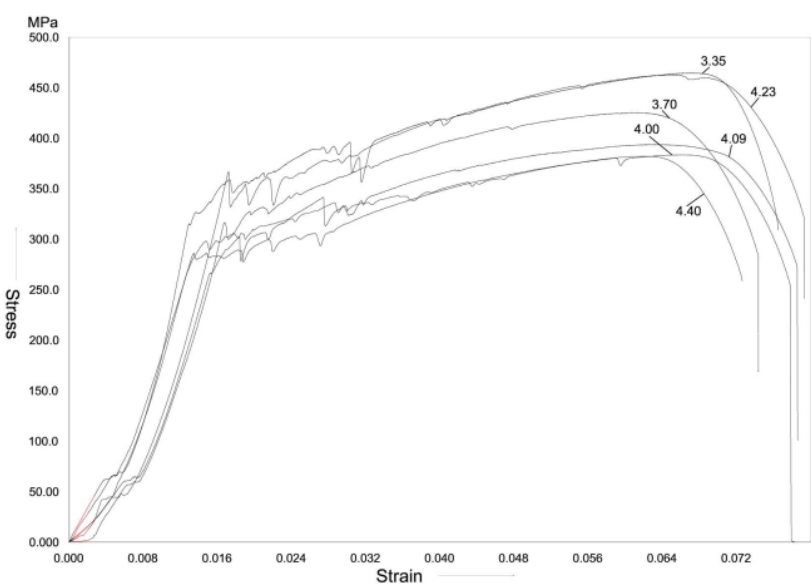

(c)

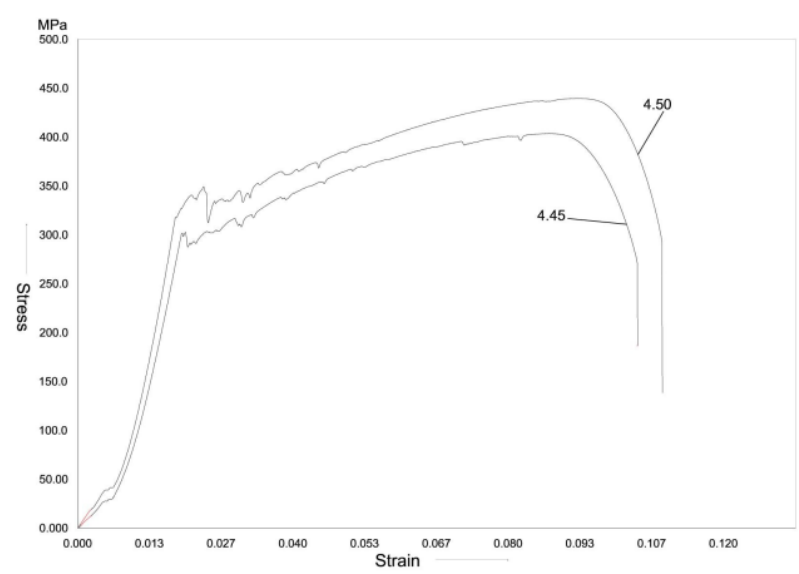

(d)

Fig. 12. Stress-strain diagrams on corroded steel specimens by minimum diameter; (a) from $1.63 \mathrm{~mm}$ to $2.70 \mathrm{~mm}$; (b) from $2.82 \mathrm{~mm}$ to $3.53 \mathrm{~mm}$; (c) from $3.35 \mathrm{~mm}$ to $4.40 \mathrm{~mm}$; (d) from 4.45 to $4.50 \mathrm{~mm}$.

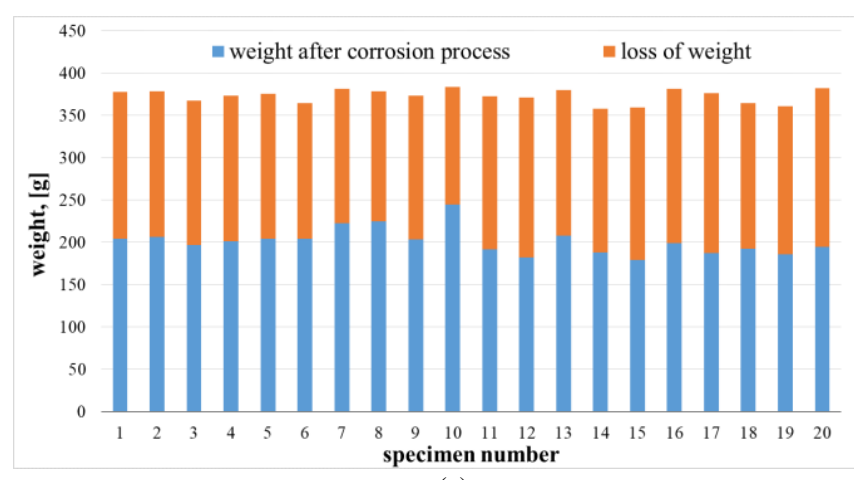

(a)

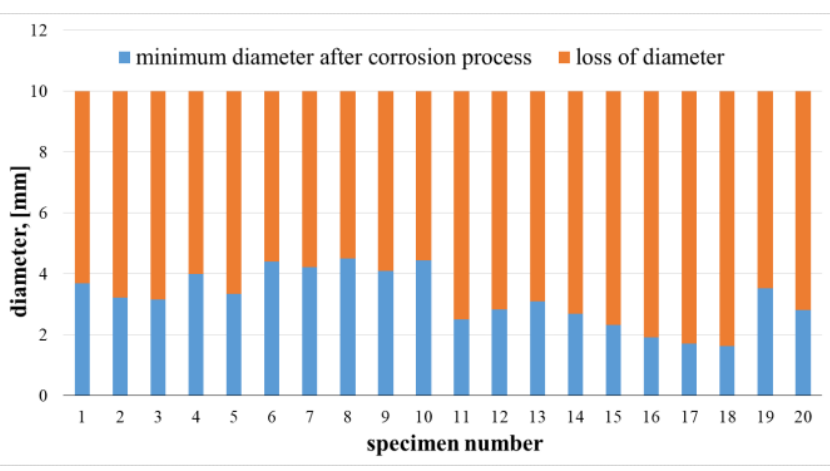

(b)

Fig. 13. Change of weight and diameter after acceleration corrosion process; (a) change of weight; (b) change of diameter.

After analysing values and diagrams it is concluded that it is possible to group through changing the diameter of the samples, not by loss of weight. Because when we need to study the stress, the area of section is important characteristic according a basic theory i.e. changing of diameter that means that is changing the area of section there from the tensions change. We make a three grouping [16,17], according to their diameter - group A (between $1.50 \mathrm{~mm}$ to $2.50 \mathrm{~mm}$ ), group B (between $2.50 \mathrm{~mm}$ to $3.50 \mathrm{~mm}$ ) and group $\mathrm{C}$ (between 3.50 $\mathrm{mm}$ to $4.50 \mathrm{~mm}$ ).

\section{B. Processing of Results from Experiment}

We use a stochastic way of processing of these results, because in the study a corroded structural steel and their parameters, it is supposed that they are independent random variables $[18,19]$. We expect to have a difference between experimental results and stochastic processing, therefore we also make an average value. The difference between our processing and real experiment data is called fluctuation or probability deviation [18].

TABLE III: STOCHASTIC RESULT

\begin{tabular}{|c|c|c|c|c|}
\hline \multirow{2}{*}{$\sigma,[\mathrm{MPa}]$} & \multicolumn{4}{|c|}{$\mathrm{E},[\mathrm{GPa}]$} \\
\hline & group A & group B & group $\mathrm{C}$ & non-corroded \\
\hline 50 & 134.65 & 119.91 & 94.83 & 96.06 \\
\hline 100 & 174.55 & 144.82 & 109.00 & 124.77 \\
\hline 150 & 199.60 & 159.90 & 134.83 & 148.32 \\
\hline 200 & 224.55 & 177.25 & 157.23 & 167.63 \\
\hline 250 & 237.00 & 192.14 & 137.16 & 183.84 \\
\hline 300 & 229.58 & 179.68 & 127.20 & 198.16 \\
\hline 350 & 234.58 & 159.63 & 114.74 & 210.65 \\
\hline \multicolumn{5}{|c|}{ TABLE IV: AVERAGE RESULT } \\
\hline \multirow{2}{*}{$\sigma,[\mathrm{MPa}]$} & \multicolumn{4}{|c|}{$\mathrm{E},[\mathrm{GPa}]$} \\
\hline & group $\mathrm{A}$ & group B & group $\mathrm{C}$ & non-corroded \\
\hline 50 & 144.13 & 131.39 & 87.37 & 96.06 \\
\hline 100 & 182.28 & 142.43 & 109.84 & 124.77 \\
\hline 150 & 199.42 & 159.51 & 134.15 & 148.32 \\
\hline 200 & 224.61 & 180.54 & 153.71 & 167.63 \\
\hline 250 & 237.38 & 195.00 & 150.36 & 183.84 \\
\hline 300 & 233.85 & 155.49 & 136.48 & 198.16 \\
\hline 50 & 144.13 & 131.39 & 87.37 & 96.06 \\
\hline
\end{tabular}


The results after processing are presented in Table III, Table IV and in graphical form in Fig. 14 and Fig. 15.

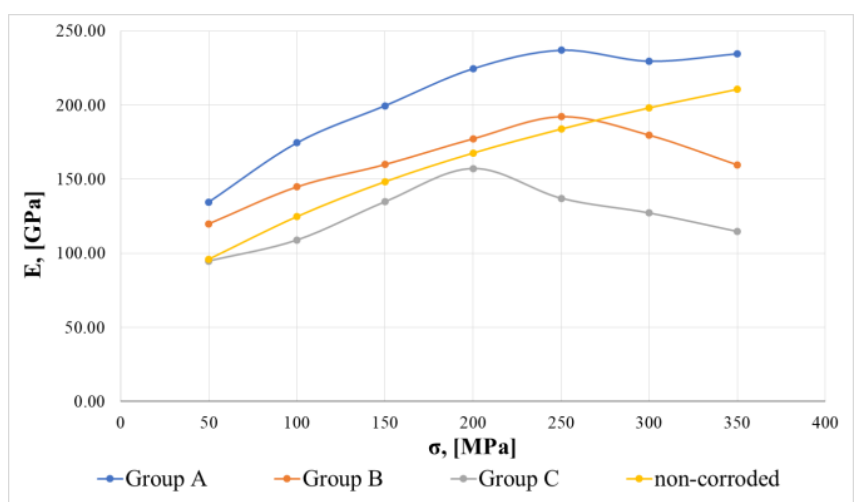

Fig. 14. Change of Young's module according stochastic results.

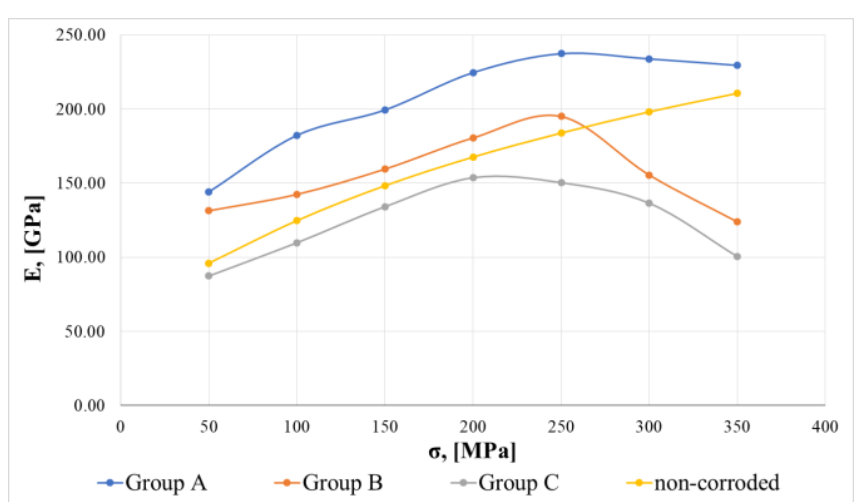

Fig. 15. Change of Young's module according average results.

As we have established from diagrams, on non-corrosive steel, the Young's module follows its linear dependence and obeys the Hooke's law. The corroded steel module is a non-linear and does not obey the Hooke's law. We are using a polynomial approximation [20] and we ascertain formulas:

- Group A (stochastic results):

$$
\begin{gathered}
E(\sigma)=9 \cdot 10^{-10} \cdot \sigma^{5}-9 \cdot 10^{-7} \cdot \sigma^{4}+0,003 \cdot \sigma^{3}-0,0502 \cdot \sigma^{2}+4,4737 \cdot \sigma \\
+3,7546
\end{gathered}
$$

- Group A (average results):

$$
\begin{gathered}
E(\sigma)=9.10^{-10} \cdot \sigma^{5}-9 \cdot 10^{-7} \cdot \sigma^{4}+0,003 \cdot \sigma^{3}-0,0595 \cdot \sigma^{2}+5,2177 \cdot \sigma \\
+5,4486
\end{gathered}
$$

- Group B (stochastic results)

$$
\begin{gathered}
E(\sigma)=6 \cdot 10^{-12} \cdot \sigma^{6}-6 \cdot 10^{-9} \cdot \sigma^{5}-3 \cdot 10^{-6} \cdot \sigma^{4}-5 \cdot 10^{-3} \cdot \sigma^{3}-0,0474 \cdot \sigma^{2} \\
-1,5564 \cdot \sigma+127,8
\end{gathered}
$$

- Group B (average results)

$$
\begin{gathered}
E(\sigma)=2 \cdot 10^{-9} \cdot \sigma^{5}-1 \cdot 10^{-6} \cdot \sigma^{4}+0,0005 \cdot \sigma^{3}-0,07765 \cdot \sigma^{2}+5,4227 \cdot \sigma \\
-1,1657
\end{gathered}
$$

- Group C (stochastic results)

$$
\begin{gathered}
E(\sigma)=-2 \cdot 10^{-11} \cdot \sigma^{6}+3 \cdot 10^{-8} \cdot \sigma^{5}-1 \cdot 10^{-5} \cdot \sigma^{4}+0,0029 \cdot \sigma^{3}-0,338 \cdot \sigma^{2} \\
+19,003 \cdot \sigma-304,49
\end{gathered}
$$

- Group C (average results)

$$
E(\sigma)=3 \cdot 10^{-8} \cdot \sigma^{4}-3 \cdot 10^{-5} \cdot \sigma^{3}+0,0075 \cdot \sigma^{2}-0,2177 \cdot \sigma+82,967 .
$$

Probability of our results - group A is $97.72 \%$, group B is $97.54 \%$ and group $\mathrm{C}$ is $97.57 \%$.

If we remove values that are non-essential (too small, or converge to zero) from the formulas, we establish with sufficient practical accuracy, a basic non-liner equation:

$$
E(\sigma)=\mathrm{A} \cdot \sigma^{3}+\mathrm{B} \cdot \sigma^{2}+\mathrm{C} \cdot \sigma
$$

where $\mathrm{A}, \mathrm{B}$ and $\mathrm{C}$ are constant values and need to be determined experimentally in every case, depending on the changes of the diameter and the corrosion resistance of steel (changing of area on section).

\section{DISCUSSION}

On non-corrosive steel, the Young's module follows its linear dependence and obeys the Hooke's law. As corrosion occurs on steel, processes within its structure begin to take place. These processes lead to a change of the Young's module and it begins to change non-linearly and does not obey the Hooke's law. The established non-linear equations are a special case and can only apply to the present study. The proposed a basic non-linear equation, formulates a formula for changing of the modulus of elasticity, which need to be studied additionally in order to offer a computational methodology that is of sufficient practical reliability. The fact that corrosion has a significant effect on the geometry of the cross-section determines that the fracture of corroded material is primarily due to the reduction of its geometrical characteristics and not its mechanical properties. The loss of elasticity in corroded elements is a factor to be investigated. This leads to a sharp change in the behavior of the material, namely the steel which is a ductile material becomes a brittle material due to corrosion and this is ascertained by the stress-strain diagrams. For corroded steel elements, brittle fracture is typical, which should be taken into account in case of re-use.

\section{CONCLUSIONS}

Our experimental study has undoubtedly established that the Young's module is changing in the presence of corrosion of steel elements. Its change is non-linear and does not obey the Hooke's law. The stress-strain diagram of the studied steel has changed significantly, which is undisputed proof that corrosion modulates the steel and leads to the loss of its elastic properties.

The strength of the material did not change significantly and/or sharply and led to the conclusion that the causes of the loss of load-bearing capacity in corroded steel elements was the fact that corrosion is reduced the geometrical characteristics (area, moment of inertia, etc.). The determination of the rate of corrosion in steel elements should not be overlooked and should be taken into account in order to assess the point at which this corroded element would not be usable, not because it would lose strength properties, but because corrosion would reduce its geometrical characteristics.

It has been found that the steel which is ductile material after corrosion has begun to change and has a brittle material behavior. This circumstance gives us reason to conclude that 
corroded steel elements for re-use may be used, taking into account that these elements have a brittle material behavior.

\section{REFERENCES}

[1] R. Ganev and G. Godiniachki, "Steel corpuses destroing from tiredness and stress corrosion," in Proc. $5^{\text {th }}$ Scientific Conference Fire and emergency safety 2009, 2009; pp. 190-192.

[2] A. Shopov and R. Ganev, "Survey on the multi-annual influence of atmospheric conditions on the strain of the reinforced steel $\Phi 6,5$ (A-I) for reuse," Annual of UACEG, vol. 51, pp. 21-28, Sept. 2018.

[3] A. Shopov, "Theoretical-calculation model for determination on stress and load-bearing capacity in rail-track with corrosion," in Proc. Conference CETRA 2018, 2018, pp. 285-291.

[4] A. Shopov, B. Bonev, and N. Brayanov, "Change of spring constant for springs with corrosion," in Proc. Conference CETRA 2018, 2018, pp. 291-297.

[5] G. Chen, M. Hadi, D. Gao, and L. Zhao, "Experimental study on the properties of corroded steel fibres," Construction and Building Materials, vol. 79, pp. 165-172, Mar. 2015.

[6] D. Ponjayuthi and K. Vinodh, "Effect of corrosion on the mechanical properties of steel reinforcement," IJCRR, vol. 8, pp. 14-20, June 2016

[7] H. Chen, J. Zhang, J. Yang, and F. Ye, "Experimental investigation into corrosion effect on mechanical properties of high strength steel bars under dynamic loadings, "International Journal of Corrosion, vol. 2018, pp. 1-12, Jan. 2018.

[8] A. Shetty, K. Venkataramana, I. Gogoi, and B. Praveen, "Performance enhancement of TMT rebar in accelerated corrosion," Journal of Civil Engineering Research, vol. 2, pp. 14-17, Feb. 2012.

[9] A. Almusallam, "Effect of degree of corrosion on the properties of reinforcing steel bars," Construction and building materials, vol. 15, pp. 361-368, Dec. 2001.

[10] Z. Zhao and L. Fu, "The probability distribution of pitting for accelerated corrosion reinforcement," Case Studies in Construction Materials, vol. 9, pp. 1-10, Dec. 2018.

[11] X. Wu, L. Li, H. Li, B. Li, and Z. Ling, "Effect of strain level on corrosion of stainless steel bar," Construction and Building Materials, vol. 163, pp. 189-199, Feb. 2018

[12] Datasheet LM317. [Online]. Available: https://www.st.com/resource/en/datasheet/lm317.pdf

[13] I. Kim, D. Dao, Y. Jeong, J. Huh, and J. Ahn, "Effect of corrosion on the tension behavior of painted structural steel members," Journal of Constructional Steel Research, vol. 133, pp. 256-268, June 2017.

[14] J. Sheng and J. Xia, "Effect of simulated pitting corrosion on the tensile properties of steel," Construction and Building Materials, vol. 131, pp 90-100, Jan. 2017
[15] G. Qin, S. Xu, D. Yao and Z. Zhang, "Study on the degradation of mechanical properties of corroded steel plates based on surface topography," Journal of Constructional Steel Research, vol. 125, pp. 205-217, Oct. 2016

[16] C. Baril, C. Casavola, and C. Pappalettere, "Corrosion effects on mechanical properties of sintered stainless steels," Procedia Structural Integrity, vol. 5, pp. 195-201, 2017.

[17] A. Shopov and B. Bonev, "Experimental study of zone of yield strength on corroded construction steel specimens for reuse," in Proc. $10^{\text {th }}$ Anniversary International Scientific Conference (Building defects 2018), 2018, pp.161-167.

[18] A. Shopov, "Stochastic way for calculation of strength on construction steel with corrosion," in Proc. XVIII Anniversary International Scientific Conference by Construction and Architecture (VSU'2018), 2018, pp. 413-418.

[19] D. Arsenjev, V. Ivanov, and M. Korenevski, Adaptive Stochastic Methods in Computational Mathematics and Mechanics, 1st ed. Berlin, Germany: De Gruyter, 2018, pp. 111-122.

[20] L.Trefethen, Approximation Theory and Approximation Practice, 1st ed. Philadelphia, USA: Society for Industrial and Applied Mathematics, 2012, pp. 175-207.

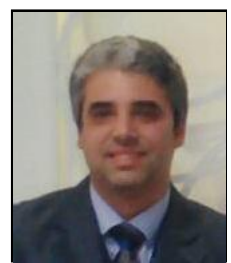

Antonio Shopov is an assistant professor at Technical University of Sofia, "Strength of materials" department, Bulgaria. He received MSc degree in Structural Engineering in 2002 from University of Architectural, Civil Engineering and Geodesy, Sofia, Bulgaria. His research interests include reused construction materials with corrosion, reconstruction and modernization of structures, steel structures and buildings.

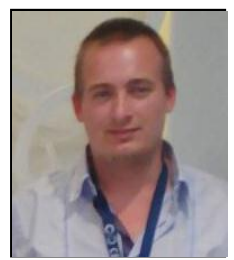

Borislav Bonev is in Technical University of Sofia, "Microelectronics" department, Bulgaria. He received a B.Eng. degree in Electronics in 2015 and M.Eng. degree in Electronics in 2017 from Technical University of Sofia, Bulgaria. He is a currently $\mathrm{PhD}$ student in Technical University of Sofia, Bulgaria. His research interests include electrochemical methods for accelerated corrosion, power electronics, microelectronics, active infrared thermography. He is author and co-author of 17 papers. 